\title{
Universal control method of auxiliary electric motors
}

\author{
A.V. Pultyakov \\ Department of automation, telemechanics and \\ communications \\ Irkutsk State Transport University \\ Irkutsk, Russia \\ e-mail: brok79@mail.ru
}

\author{
M.P. Dunaev \\ Department of electric drives and electric transport \\ Irkutsk National Research Technical University \\ Irkutsk, Russia \\ e-mail: mdunaev10@mail.ru
}

\author{
G.O. Arsentyev \\ Department of power supply and electrical engineering \\ Irkutsk National Research Technical University \\ Irkutsk, Russia \\ E-mail: arsentyevov@mail.ru
}

\begin{abstract}
To control the angular velocity of the auxiliary electric motors of electric locomotives, controlled converters are used, making it possible to implement various methods for controlling the electric motors of direct and alternating current. Depending on the technical and technological conditions, different types of controlled converters can be used, and the strictest requirements for controlled converters are imposed at railways. Advantages of converters with resonant inverters, especially a reliable natural turning-off of thyristors and the possibility of obtaining a sine wave form output voltage, make it possible to apply them in DC and $\mathrm{AC}$ electric drive systems in railway transport.
\end{abstract}

Analysis of the main methods of controlling the rotational speed of AC and DC electric drives made it possible to reveal the advantages and disadvantages of existing control methods and to concentrate attention on the most promising ones, which include the control method using the pulse-width modulation and the control method using pulse-frequency modulation.

The proposed universal method of controlling DC and AC electric drives has the advantages of the known control methods and it is based on the application of resonant inverters circuits.

The results of the research give grounds to assert the possibility and feasibility of controlling $\mathrm{AC}$ and $\mathrm{DC}$ electric drives by means of circuits of resonant series inverters that allow controlling such basic parameters as the average value and voltage frequency of the motor.

Keywords - electric motor; converter; control; resonant inverter.

\section{INTRODUCTION}

To control auxiliary electric motors of electric locomotives, various controlled converters (CC) are used, making it possible to implement one or another method for controlling the electric motors of direct and alternating current. Depending on the technical and technological conditions, different types of controlled converters can be used, and the strictest requirements for controlled converters are imposed at railways.
The carried out analysis [3] shows that the main methods for regulating the parameters of electric drives (ED) of direct current are: a method of phase adjustment (PA) of rectified voltage, a method of pulse-width modulation (PWM) of direct current voltage, a method of pulse-frequency modulation (PFM) of direct current. The main methods of adjusting the parameters of drives of alternating current are: a method of phase adjustment of variable voltage, a method of amplitudefrequency adjustment (AFA) of variable voltage, a method of phase-frequency adjustment (PFA) of variable voltage, a method of pulse-width modulation of alternating current voltage.

The technical characteristics of the main types of DC and AC controlled converters are presented in Table I, where CR controlled rectifier, PWC - pulse-width converter, PFC pulse-frequency converter, VR - voltage regulator, FC - frequency converter with DC link, DFC is a direct frequency converter.

Analyzing Table I, it can be concluded that the best method is the control method with PWM. This method makes it possible to create the required wave form of the motor supply voltage $U_{\text {mot }}$ to achieve high smoothness and a wide range of angular velocity control $R_{\text {control }}$ at constant $\cos \varphi$ and low distortion level of the power supply system.

Unfortunately, the control method with PWM has a number of disadvantages: a slight decrease in efficiency of the frequency converter, more complex control algorithm $[9,10]$, high cost of power switches (transistors), an increased level of electromagnetic interference.

However, there is another method of pulse control (PFM), represented in Table I by a frequency pulse DC converter (FPC), which is more promising than the PWM method. We consider the circuits of converters based on resonant inverters as a possible version of the technical implementation of the control method with PFM. 
TABLE I. THE TECHNICAL CHARACTERISTICS OF THE MAIN TYPES OF DC AND AC CONTROLLED CONVERTERS

\begin{tabular}{|c|c|c|c|c|c|c|c|c|c|}
\hline $\begin{array}{c}\text { Type } \\
\text { of the } \\
\text { controlled } \\
\text { converter }\end{array}$ & $\begin{array}{c}R_{\text {control }} \\
\text { of angular } \\
\text { velocity }\end{array}$ & $\begin{array}{c}\cos \varphi \\
\text { of power } \\
\text { supply } \\
\text { system }\end{array}$ & $\begin{array}{c}\text { Smoothness of } \\
\text { regulation }\end{array}$ & $\begin{array}{c}\text { Form of } \\
U_{\text {motor }}\end{array}$ & $\begin{array}{c}\text { Distortion } \\
U_{\text {system }}\end{array}$ & $\begin{array}{l}\text { Electromagnetic } \\
\text { interference }\end{array}$ & $\begin{array}{l}\text { Complexity } \\
\text { of CC }\end{array}$ & $\begin{array}{c}\text { Efficiency } \\
\text { of the CC, \% }\end{array}$ & $\begin{array}{l}\text { Control } \\
\text { method }\end{array}$ \\
\hline CR & wide & lowers & high & undesired & high & high & low & 98-99 & PA \\
\hline PWC & wide & constant & high & required & low & high & low & $96-97$ & PWM \\
\hline PFC & restricted & increases & high & required & low & low & low & 97-98 & PFM \\
\hline VR & restricted & lowers & high & undesired & high & high & low & 98-99 & PA \\
\hline FC & restricted & lowers & high & undesired & low & high & low & 96-97 & AFA \\
\hline $\begin{array}{l}\text { FC with } \\
\text { PWC }\end{array}$ & wide & constant & high & required & low & high & high & $95-96$ & PWM \\
\hline DFC & wide & lowers & low & undesired & high & high & high & 98-99 & PFA \\
\hline
\end{tabular}

\section{CONVERTERS WITH RESONANT INVERTERS}

Advantages of converters with resonant inverters, especially a reliable natural turning-off of thyristors and the possibility of obtaining a sinusoidal wave form of output voltage, allow using them in DC and AC drive systems [3].

To control the angular velocity of the motor in DC drives, various methods for regulating the voltage on the motor are implemented in particular using pulse-frequency converters [3, 7].

Such converters, built on bridge or other single-phase circuits of series inverters, operate in a pulsed mode, when pulse width remains constant and the pulse repetition frequency changes. The disadvantage of such circuits are a relatively low output pulse repetition frequency, that does not allow achieving high speed of the electric drive, as well as an unfavorable operation mode of the thyristors due to the non-sinusoidal wave form of the output voltage pulses and the short time of their locking.

The application of resonant inverters in PFC allows receiving across load voltage pulses close to the sinusoidal wave form that improves the operation of the circuit thyristors. The advantage of resonant inverters is also proved by the fact that PFC circuits based on resonant inverters have a high output frequency. However, single-phase circuits of resonant inverters have certain limitations of the output frequency and power associated with the frequency characteristics and load characteristics of the thyristors used.

It is the application of three-phase resonance series inverters that allows to significantly improve the speed and power of the PFC [3].

At present, the most developed methods are those of controlling AC electric drives when the angular velocity of the motor is controlled by changing frequency and average value of the supply voltage $[4,5]$.

It is also possible to use a converter with a three-phase thyristor resonant series inverter to adjust the angular velocity of an asynchronous motor [6]. The rotational speed is controlled by changing the output frequency of the inverter powered by an uncontrolled rectifier. The average voltage value at the output of the inverter is then proportional to the output frequency, i.e. this regulation takes place under conditions close to the automatic stabilization of the magnetic flux of the motor and consequently the constant torque of the motor shaft. Let us note that in other systems of frequency converters maintaining a constant voltage - frequency ratio requires a special control algorithm, often associated with a rather complex technical implementation $[2,4]$.

We note the advantages of converters with resonant inverters [3]:

- Reliability of power circuit, caused by the use of close to natural series switching of thyristors.

- Increase of the converter efficiency due to a lower voltage drop across the open thyristor in comparison with the transistor and a favorable operation mode of the thyristors due to the sinusoidal wave form of the output voltage pulses.

- Use of a relatively simple inverter circuit (including a control system) that allows approximately three times to reduce such an economic indicator as the converter's cost per 1 $\mathrm{kW}$ of power in comparison with converters on IGBTtransistors. At the same time, according to the main technical parameters of regulation, such as the range of output frequency variation and the smoothness of regulation, this converter is comparable with known circuits of frequency converters.

- Improvement of power factor of the electric drive due to the presence of capacitors in the power circuit of the inverter.

The results of research of the use of three-phase resonant inverters for controlling $\mathrm{DC}$ and AC motors make it possible to propose a universal method for controlling DC and AC electric drives. This method is based on the use of three-phase resonant series inverter circuits to control such basic parameters as the average value and the frequency of the output voltage.

The essence of this method consists in the fact that the same power supply circuit of a three-phase resonant series inverter can be used to control the rotational speed of both DC and AC motors [3]. We can take as an example the circuit in Fig. 1, which is used as a direct current converter (DCC) for controlling a DC motor (DCM). 
In the circuit in Fig. 1, the DC load is included in the circuit of the pulsating input current of the inverter bridge and the average voltage in the load Uav (1) depends on the switching frequency of the thyristor pairs $\omega$.

$$
U a v=K \omega,
$$

where $K$ is the voltage gain of the PFC.

The task of controlling the DC motor can be completely solved by effecting its armature winding by an average voltage controlled by frequency $\operatorname{Uav}(2)$ :

$$
\Omega=[\operatorname{Uav}-\operatorname{Iav}(R c+R a)] / C,
$$

where $\Omega$ is the rotational speed of the DC motor, Iav is the average armature current, $R c$ is the internal resistance of the PFC, $R a$ is the resistance of the armature of the DC motor, and $C$ is the DC motor constant.

The required static and dynamic characteristics of a DC electric drive with a three-phase resonant series inverter are created by means of necessary feedbacks, in particular with respect to the current and angular velocity of the motor, and the use of regulators in the control system with the appropriate settings.

We consider then the application of the circuit in Fig. 1 as a frequency converter for controlling an $\mathrm{AC}$ motor, for example, an asynchronous motor (AM). We include the stator windings of the $\mathrm{AM}(\mathrm{Z1}, \mathrm{Z2}, \mathrm{Z3})$ in the diagonal of the alternating current of the inverter bridge, as shown in Fig. 2.

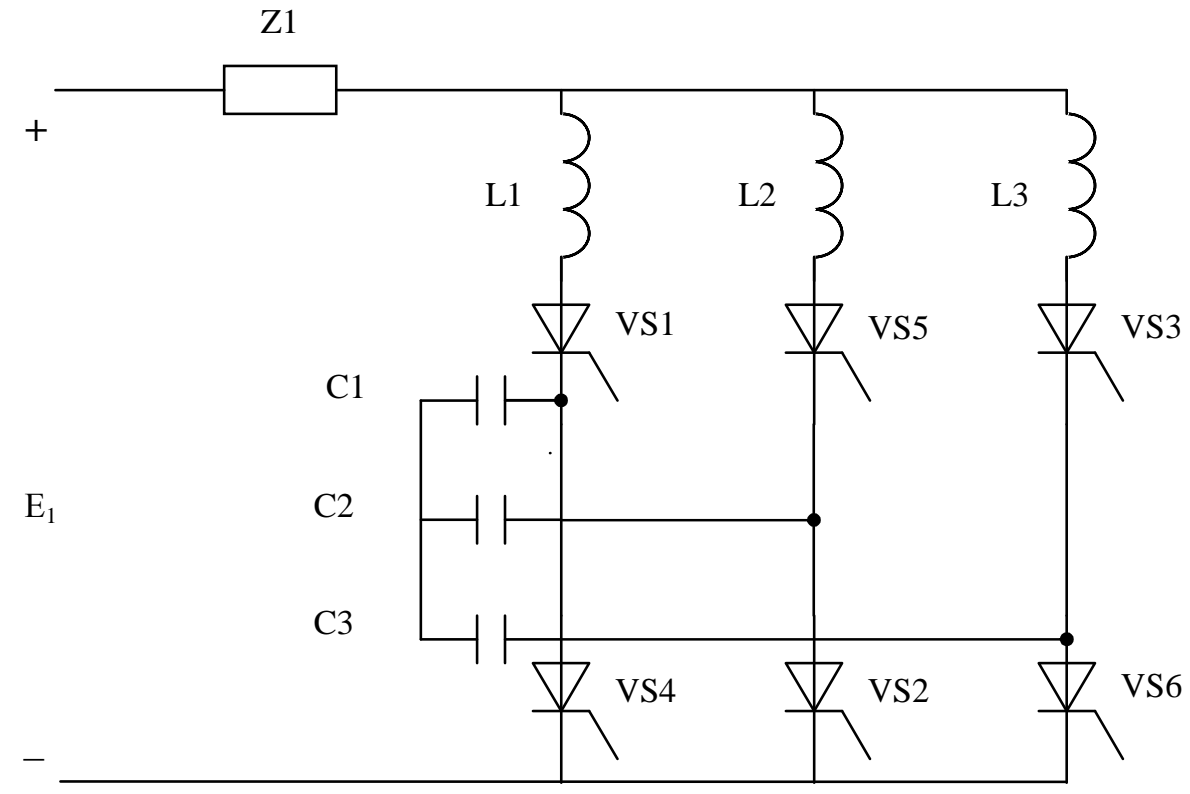

Fig. 1. Circuit of PFC with resonant inverter.

In this case, a rotating magnetic field with the switching frequency of the pairs of thyristors $\omega$ is created in the stator windings. The rotational speed of the AM is controlled by changing the output frequency of the inverter $\omega$, and the average voltage value of the stator windings Ulav will be proportional to the output frequency, i.e. the ratio $U 1 a v / \omega$ required to provide the constant torque of the motor shaft is automatically maintained.

However, such simple control algorithm has certain disadvantages. The first one is that the deep control of the rotational speed of the AM decreases the maximum torque developed by the motor. The second drawback is due to the fact that at low output frequency of the inverter, an irregularity of the motor rotation appears, that is a side effect of the impulse regulation Ul av.

These disadvantages can be eliminated by applying a pulse-frequency modulation method to create the necessary wave form, amplitude and frequency of the converter's variable output voltage. Consider the circuit in Fig. 3, consisting of two circuits of three-phase inverters (Fig. 1). Both circuits operate alternatively, creating in the load Z1 a frequencymodulated average voltage of a sinusoidal wave form. The voltage diagrams for the load in the circuit in Fig. 3 are shown in Fig.4. 


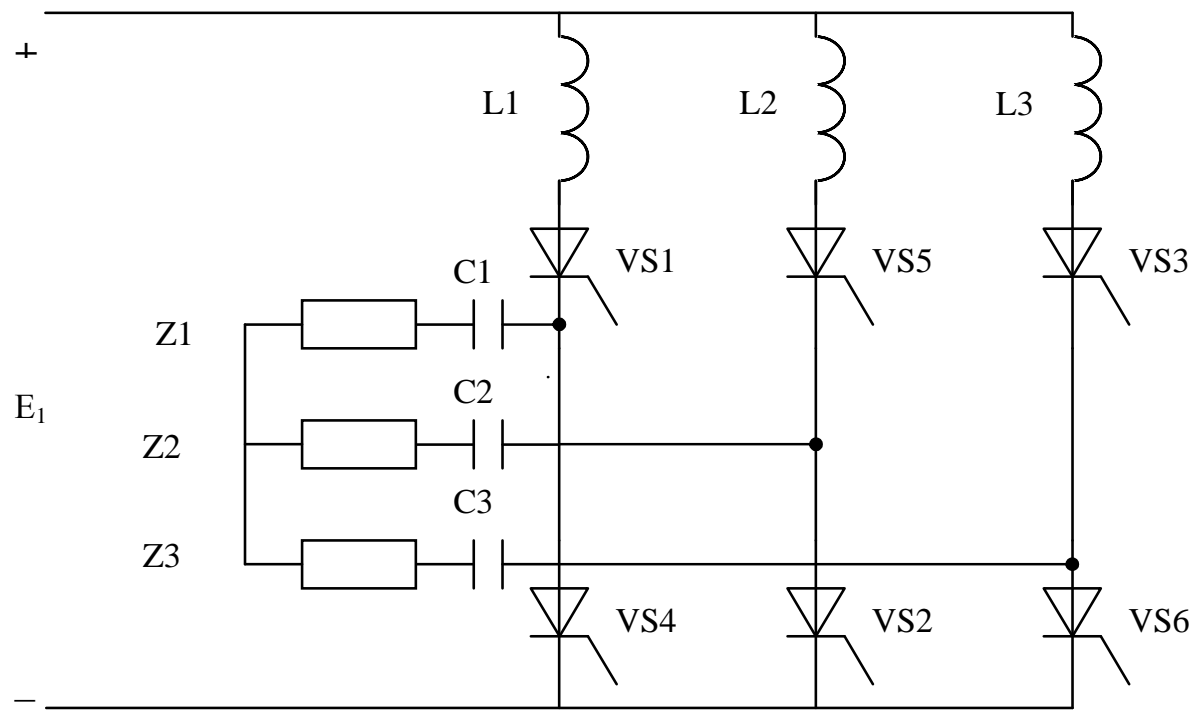

Fig. 2. Circuit of FC with resonant inverter.

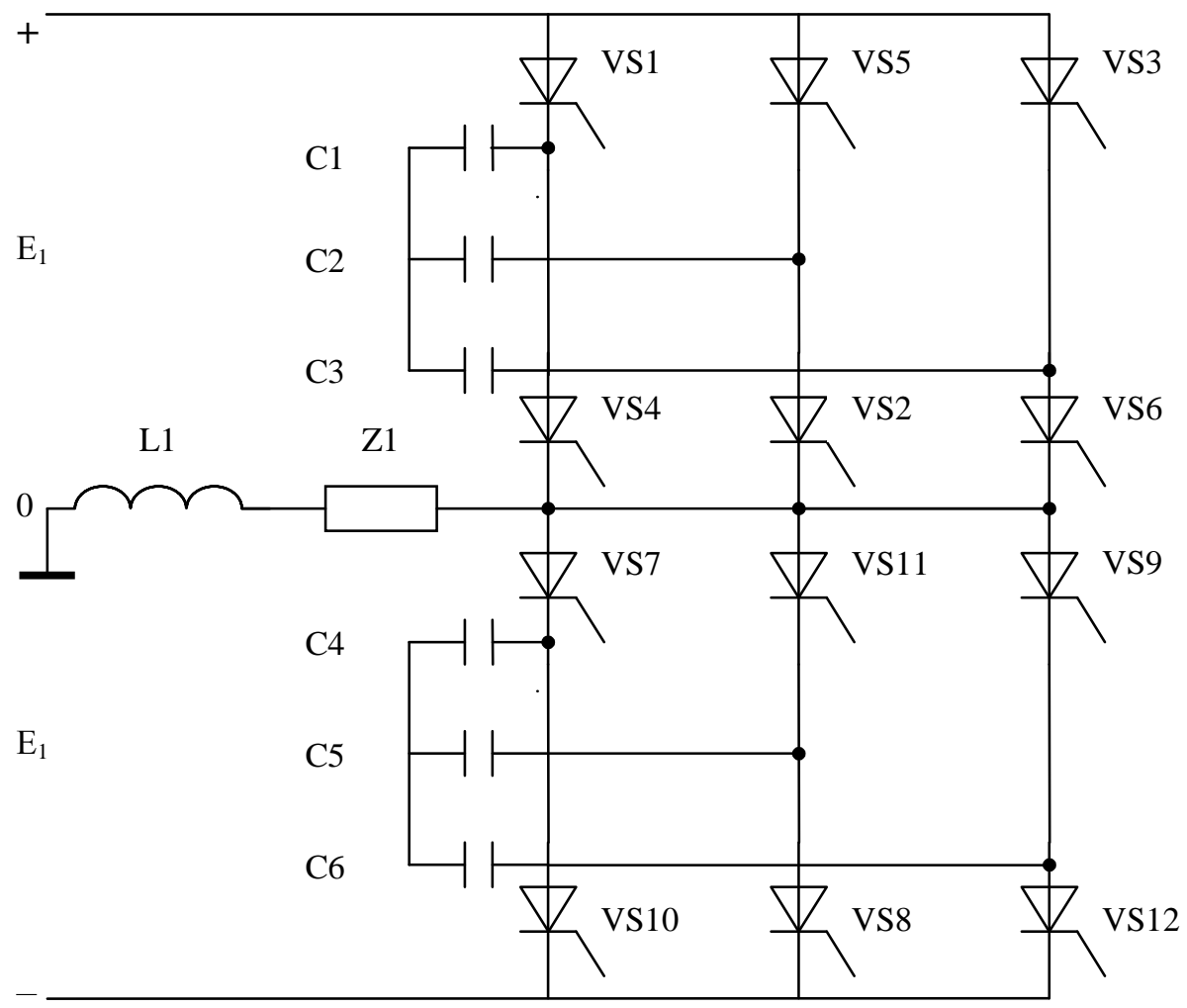

Fig. 3. Circuit of FC with PFM. 


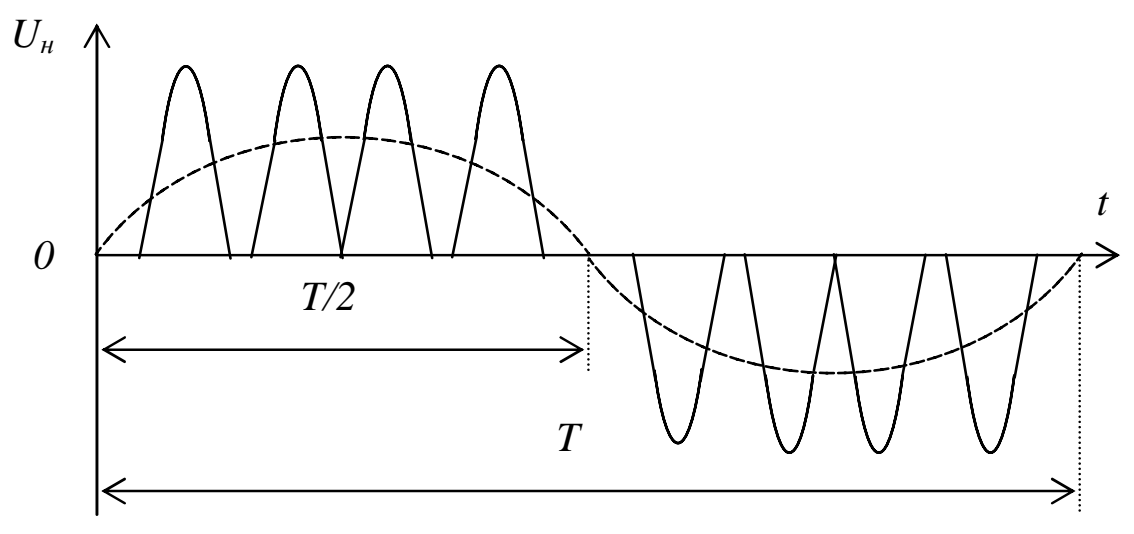

Fig. 4. Diagrams of FC with PFM.

\section{CONCLUSION}

The analysis of the main methods of controlling the rotational speed of AC and DC electric drives made it possible to reveal advantages and disadvantages of existing control methods and to concentrate attention on the most promising ones, which include the control method using pulse-width modulation and the control method using pulse-frequency modulation.

The proposed universal method of controlling DC and AC electric drives has the advantages of the known control methods and it is based on the application of resonant inverters circuits.

The results of the research give grounds to assert the possibility and feasibility of controlling AC and DC electric drives by means of circuits of resonant series inverters that allow controlling such basic parameters as the average value and the voltage frequency of the motor.

\section{References}

[1] N.F Ilyinsky, "Prospects for the development of a regulated electric drive," Electricity, vol. 2, pp. 3-8, 2003.
[2] A.V. Kryukov, V.P. Zakaryukin, N.A. Abramov, Operation of traction power supply systems. Situational approach, Saarbrücken: LAP LAMBERT Academic Publishing, 2011.

[3] M.P. Dunayev, Resonance inverters for controlling electric drives, Irkutsk: IrSTU, 2004.

[4] V.I. Kochergin, The theory of multidimensional digital sets in applications to electric drives and power supply systems, Tomsk: Tomsk State University, 2002.

[5] S.N. Florentsev, "State and perspectives of the development of devices of power electronics at the turn of the century," Electrical Engineering, vol. 4, 1999, pp. 2-10.

[6] A.I. Balabukh, M.P. Dunaev, E.G. Livshits, "Three-phase series inverter," Bulletin of Inventions, vol. 45, 1982.

[7] O.G. Bulatov, A.I. Tsarenko, Thyristor-capacitor converters, Moscow: Energoatomizdat, 1982.

[8] M. Irwanto, H. Alam, M.Y. Mashor, M. Masri, A.H. Haziah, B. Ismail, A.H. Butar-Butar, "Analyzes of AC voltage and current wx/aveform distortion on SPWM transformerless photovoltaic inverter," Far East Journal of Electronics and Communications, vol. 17-5, 2017, pp. 11671176.

[9] V.S. Mariyukhnenko, S.A. Dudin, V.V. Truskova, "System analysis of the human operator in an automated control system," Modern Technologies, System Analysis, Modeling, vol. 2, 2014, pp. 143-150.

[10] Yu.F. Mukhopad, Theory of Discrete Devices, Irkutsk: IrGUPS, 2010. 